\title{
POSSIBILITIES OF USING AUGMENTED REALITY IN WAREHOUSE MANAGEMENT: A STUDY
}

\author{
Jozef Husár \\ The Technical University of Košice, Faculty of Manufacturing Technologies with a seat in Prešov, Department of \\ Industrial Engineering and Informatics, Bayerova 1, 08001 Prešov, Slovak Republic, EU, \\ jozef.husar@tuke.sk

\section{Lucia Knapčíková} \\ The Technical University of Košice, Faculty of Manufacturing Technologies with a seat in Prešov, Department of \\ Industrial Engineering and Informatics, Bayerova 1, 08001 Prešov, Slovak Republic, EU, \\ lucia.knapcikova@tuke.sk (corresponding author)
}

Keywords: warehouse management, augmented reality, Pick-by-Vision system, smart glasses

Abstract: The presented manuscript points to the possibilities of implementing Smart glasses in warehouse management. With the introduction of augmented reality (AR), it is possible to speed up warehouse employees' processes must ensure significantly. The first part of the article deals with the issue of augmented reality and the object sensing system. The second part is focused on the possibilities of AR in warehouse management to increase productivity. The main part of the study focuses on comparing four systems that operate in distribution centres. The study evaluated and described the benefits of their implementation. Overall, the findings show that the performance of Smart technologies focusing on augmented reality is becoming a novelty in warehousing with significant services for businesses. AR is also pointed out by implementing Industry 4.0 ideas in the concept of creating digital twins of manufacturing companies, which is a current trend.

\section{Introduction}

The time we live in is technologically advanced and offers us new challenges. Augmented reality as a form of perception of the environment is its result. It provides us with a worldview that enriches us to create added value for society. Currently, the display of reality with added objects is very popular and trendy. Therefore, this article's main purpose is to analyse the use of augmented reality in warehousing as a tool to facilitate the activities of employees in a human-warehouse relationship. Perception of augmented reality we can say that we use a mobile display unit to display 3D models and information. A mobile phone, tablet and smart glasses can serve as our unit.

\section{Division according to AR display}

The technology we use to display augmented reality includes:

- Imaging device - we consider it a camera or a camera that captures the real environment.

- Computing devices - smartphones, tablets, computers, and other similar devices that perform software operations.

- Imaging device - its task is to draw the resulting image. These are devices such as a monitor, projector, HMD glasses, smartphone or tablet.

AR's accessibility to the general public is the result of an advanced time that has given us such devices that can operate easily and contain all three components working synchronously and together. Tracking, tracking or in full translation capture is the process of recognising, scanning, segmenting and analysing the environment performed using a camera and various sensors (GPS sensor, accelerometer, gyroscope, digital compass, etc.) [1].

The blog blippAR.com writes that augmented reality can be divided into three basic methods according to how digital objects are displayed. Let's look at the options we know to start displaying digital content [2].

\subsection{Marked-Based AR}

Marker-based AR or augmented reality based on markers is a typical way that real-time object tracking can work. The marker is the starting point and characteristic of this method. It can be characters, pictures, and real objects, whose main task is to carry digital information. The technology uses a marker to recognise the position, orientation of an element in space, or other properties that describe an object. Subsequently, using the software makes it possible to turn the marker into a digital item using AR. Markers also developed, which led to the fact that any image, even a living element of the physical world, could be considered a marker. Bar codes and later QR codes are considered among the first markers. Clear development and division of markers into groups was prepared by Professor Vladimir Geroimenko and shown in the following diagram in Figure 1 [3]. 


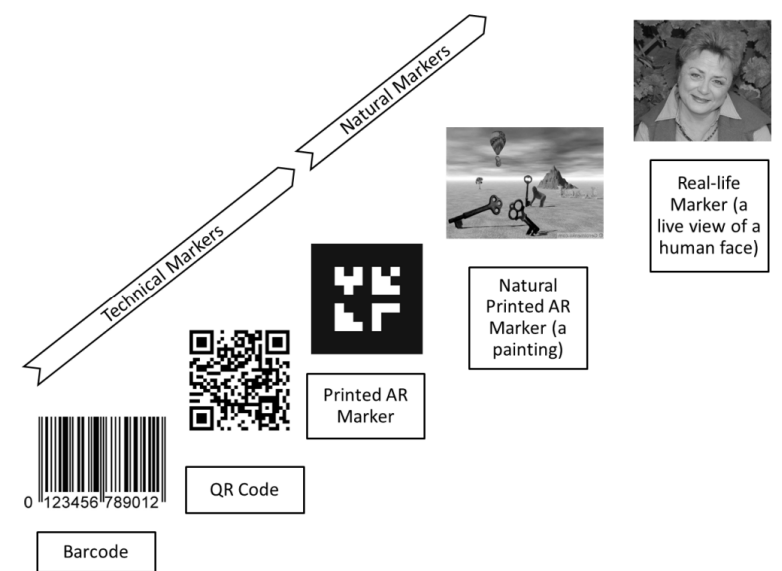

Figure 1 Development of markers according to V. Geroimenko [3]

To better understand the use of marker-based AR, we can give an example with animation in a book: If we want to display an educational application in a book, the user must have a device with appropriate software and a camera. The user must recognise this marker on the relevant side, where a distinctive image serves as a marker, and point the device's camera at it. Subsequently, a digital visualisation will be displayed, i.e. an animation hidden in the appropriate tag. The user can also move through the physical book and see how the virtual object "holds" on the page's actual surface [2].

\subsection{Markerless - Based AR}

As the name implies, we can deduce that markerless AR applications do not use markers to recognise and mediate augmented reality. This augmented reality method does not require prior knowledge of the user environment for the 3D content to occur and be held in a fixed place in space. It is a method where the user can move entire virtual objects in a real environment. We will also give an example to clarify this way of displaying AR: Imagine an application that can help us furnish an apartment's interior. The application must be available on a device with a camera; the most commonly used are smartphones or tablets. Subsequently, the user must decide where to insert the virtual object (in our case furniture), and the camera captures the space. The table does not float when stored in the area; we can anchor it on a flat surface for a realistic idea. Many such markerless AR applications are more accessible to the general public, especially on smartphones.

\subsection{Location - Based AR}

This kind of augmented reality does not need markers to track. Position recognition is important. Spatial orientation is performed using GPS coordinates, electronic gyroscope or compass. Location-based AR is more suitable especially for the exterior. A device using this AR method knows with sufficient accuracy where it is located or rotated. As with the previous types, it is better to understand AR's workings with an example: Imagine we are walking down an urban street. We see a landmark we would like to know more about. A device with the appropriate location-based AR application registers a virtual tag with the camera. It will then display information about the object. However, to ensure that digital AR content appears in the right place, your device must pinpoint its location. The Pokemon GO application is also known for this way of displaying AR [4].

\section{Division according to the use of the senses}

Defining the division of AR according to the senses is shown in Figure 2, which depicts all kinds of reasons that a person can perceive and the corresponding kind of augmented reality.

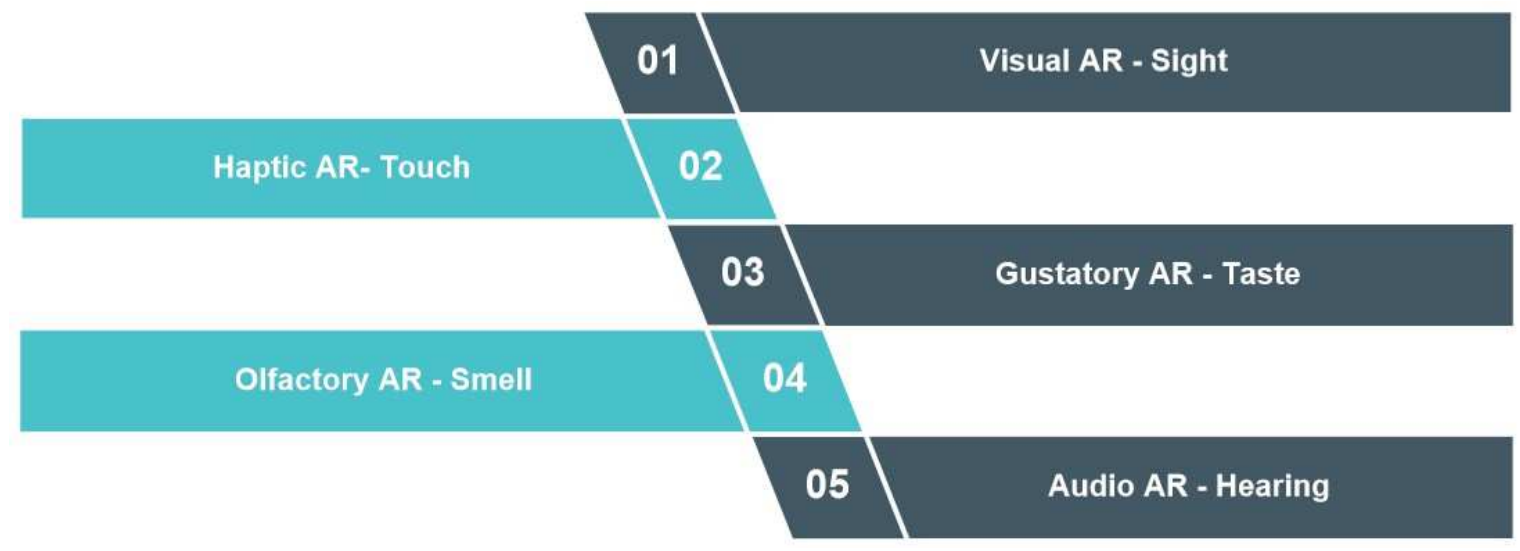

Figure 2 Augmented Reality divided according to senses [5]

- Visual AR - Most of the information a person has visually acquired. AR enhances the visual sense and allows people to see the digital and physical worlds simultaneously. It is the most common way of administering AR, applicable almost everywhere.

- Audio AR - Audio-transmitted AR mainly uses glasses and headsets to, e.g. the workers had their 
hands free and could operate the handling equipment. The kit has the attenuating effects of external background noise and can provide product information at work.

- Haptic AR - This AR is based on tactile sensors and their feedback. It can play an important role in medicine by using $5 \mathrm{G}$ haptic gloves in remote surgery and teaching doctors in large numbers through realtime professional cooperation.

- Olfactory AR, Gustatory AR - Smell and taste are theoretically also usable in augmented reality, but at the moment they are just thoughts of the future. It is assumed that these types of AR could sensory identify the threat in the company. According to the blog of the ericsson.com portal, they are more likely to be used in the gaming industry, to improve the enjoyment and enjoyment of the game [5].

\section{Division according to the way the image is joined}

There are three different ways to combine a physical environment image and a virtual environment image. We know the so-called "See-through AR" (optical and video display) and "Spatial AR" (PA model) [6].

\section{OPTICAL SEE-THROUGH}

This optical display method uses normal or semitransparent mirrors to display the real environment. The virtual object is implemented in these mirrors, and thus the real and digital world and its combination are connected. It belongs to the older ways of clicking the image, today we already know much more advanced methods.

\section{VIDEO SEE-THROUGH}

A well-known system using a camera for recording the surroundings, where the connection and display of the relationship between the digital and real image on the display is performed utilising a computing device (e.g. smartphone, tablet). The great advantage of this system is the possibility of interaction with augmented reality.

\section{Projection augmented models (PA Model)}

Spatial AR is a type of augmented reality where computer-generated information is projected directly into the user environment. The PA model belongs to this ARtype and is closely related to the tactile user environment (TUI). TUI was developed by Hiroshi Ishii, a professor at MIT Media Laboratory, who presents tangible bits as a vision that seeks to give a physical form of digital information. The bits can then be directly manipulated and tactile, thus seeking a seamless connection between physical and virtual objects [7].

The PA model can be understood as imaging using a projector, where the object can be projected directly into the real environment on a wall, objects or as a hologram. According to Di Donat, when casting on a wall or on objects, it is not always necessary to speak of AR, but this is quite certain [8].

\section{Methodology}

Picking goods is one of the most important phases and operations in the warehouse, where proper warehouse logistics can save the company considerable financial costs. This initial phase of fulfilling a customer order is most important, as it is essential for the functionality of other processes such as order packaging, shipping, and after-sales activities. Besides, this basic warehousing process covers the highest part of the warehouse's operating costs and expenses. Therefore, the selection of goods from the warehouse, respectively. Picking must be flawless, and automated systems and technology are also needed to streamline the whole process. In this area, augmented reality is engaged and implemented as a management tool for picking goods.

To streamline and speed up the entire order picking process, employees are looking for ever newer solutions through new technologies and picking systems [9]:

- The Pick-by-Paper system is a traditional way for employees to remove goods from the warehouse. In their work, they use a paper list of goods, which contains the number of goods, the number of required pieces and the location in which the assortment is located. Working with such a system is inefficient and very laborious.

- $\quad$ The RF picking system is a very popular picking system, where all products must be marked with RFID codes. Using radiofrequency mobile devices terminals, the appropriate RFID code is scanned from the tag, and then the action is performed. RFID scanning can be easily disturbed by the close presence of some devices, amounts of fluids or metals.

- The Pick-by-Light system is more difficult to install, as you need barcode scanners and special LEDs located directly on the shelves and racks of the warehouse, so this system is costly.

- The Pick-by-Voice system is another way to help an employee and streamline their work in selecting and picking goods through a headset that provides him with an input flow of information and instructions. This system's disadvantage is the impossibility of use in a noisy environment because the employee would not hear instructions from the system.

- Pick-by-Vision system

It is the Pick-by-Vision system that will interest us from the perspective of augmented reality. It is one of the most modern techniques for the order picking process and differs significantly from the systems mentioned above. The interest of this system supported by augmented reality is navigation based mainly on visualisation, which can be divided into 3 types, which are mutually supported [10]:

- Meta navigation- Draws the user's attention to objects that are out of the HMD's field of view at a particular time.

- Rough navigation - The goal is to transport the user to the correct aisle and shelf of the warehouse. 
- Fine navigation - From it, the user has the best experience of augmented reality, because the system navigates him directly to the field he needs. Subsequently, he can pick up the goods from the found box.

With augmented reality, Vision picking has created a completely new way of managing warehouses and has made it possible for many companies to streamline their accuracy and productivity level. This relatively new technology advances warehouse management by saving manual effort, time, and eliminating individual errors. There are development companies on the market. There are currently systems from Knapp, SAP, DHL and Ubimax creating an extended environment using HMD for the pickby-vision system, from which large companies can choose to address them [11].

\section{Results and Discussion}

In terms of sales and logistics, the two areas are closely linked. The importance of logistics for total sales lies in the speed and efficiency of the delivery of goods in a warehouse-customer relationship. This section will look at how the logistics process has changed and how AR technology is implemented in this area.

In recent years, the entire logistics process has been technologically improved by transforming and digitising various processes, resulting in Logistics 4.0. [12]. Technological improvements can also be seen in the introduction of advanced computer vision techniques, such as augmented reality. It can influence and streamline key processes in the warehouse, such as collecting, sorting, and loading goods. This technology makes the warehouse smarter by making it easier for operators to pick goods, show them the right way to sort the range, help operators load goods in the best possible order, and identify and alert the risk of damage when distributing goods [13]. All this is done with IoT, which helps us connect devices, objects and people to the Internet. In warehouses, this will provide much faster access to data and information. There are many possibilities for using augmented reality in the logistics system, but the most common is vision picking. As mentioned above, pick by vision is mediated by an HMD display, i.e. smart glasses of various brands. This article focuses on vision picking, which describes in detail the use of pick-by-vision by DHL, which has long been involved in developing this innovation and, in addition to annual reports, also provided an expert study on this topic. We also know other companies in the world known for implementing such tools to support and streamline the entire logistics process [14].

\subsection{Vision picking by $\mathrm{DHL}$}

DHL's global supply chain is one of the first companies to introduce augmented reality technology into the Vision Picking program. In cooperation with Google, Vuzix and Ubimax, it was first tested in 2014 at the Dutch DHL plant. The entire system runs on a platform from Ubimax, where a worker uses Google Glass or Vuzix smart glasses and a ring scanner to pick up goods. These devices provide the operator with several functions and information. The first step for working with the system is to log in the operator and turn on the necessary equipment. After being greeted by the device, the user selects an available cart to pick and scans it into the machine. A visual aid is graphically displayed through the glasses, where you will find the information needed to pick up the order. The user sees the aisle number in the graphical tool, the exact allocation of the goods, the quantity he has to select, and the next item. This information accurately, quickly and efficiently guides the worker to a given order item. Therefore, this method of picking goods is much more efficient than the classic paper form of picking. After reading the item's barcode with glasses, the system automatically indicates in which of the boxes on the cart the item should be inserted and in what number. The system knows exactly the position of the boxes on the trolley. By using the headset, the worker's hands are released, so he can work more efficiently. The visual aid in the glasses helps sort the products (Figure 3), thus ensuring the speed and overall quality of work. Regarding training workers and comprehensive integration into the work process, we can say that this technology is not difficult to use and will be quickly adopted by the worker. DHL's vision is to integrate AR into the entire process of distributing goods in the warehouse across multiple operations to increase and improve customer benefits [15].

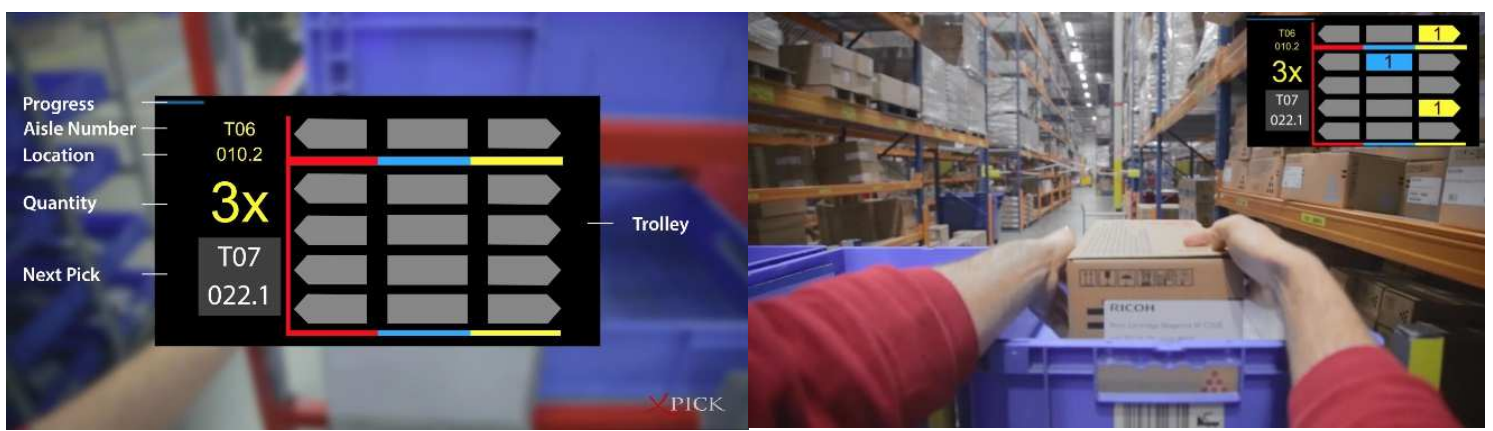

Figure 3 DHL Vision Picking [15] 
DHL is considered to be one of the first companies to address the topic of augmented reality through pick-byvision in logistics. However, we also know other world giants in their field who have also started picking goods using this technology because they saw potential. All the companies use xPick from Ubimax for picking goods, as well as DHL, xPick. This augmented reality solutions company is among the best in its field. Because all selected companies use xPick, the way the software works and works is very similar.

\subsection{Samsung SDS}

SAMSUNG SDS is a subsidiary of Samsung Corporation, which develops and researches new information technologies such as IoT, AI, Blockchain and the like. As part of the Samsung Cello project, they introduced vision picking in 2015 and incorporated it into their intelligent storage program at a European distribution centre in the Netherlands. The entire technology runs on the Ubimax platform. After switching on the device, the user starts picking the goods by finding the goods' position using smart glasses. Employee checks (Figure 4) the number of the selected goods if everything fits, he confirms it with a smartwatch and enters the number. The employee continues by checking the other goods with glasses and going over them. The visual aid mediated by the glasses provides information to a similar extent as in the DHL system [16].

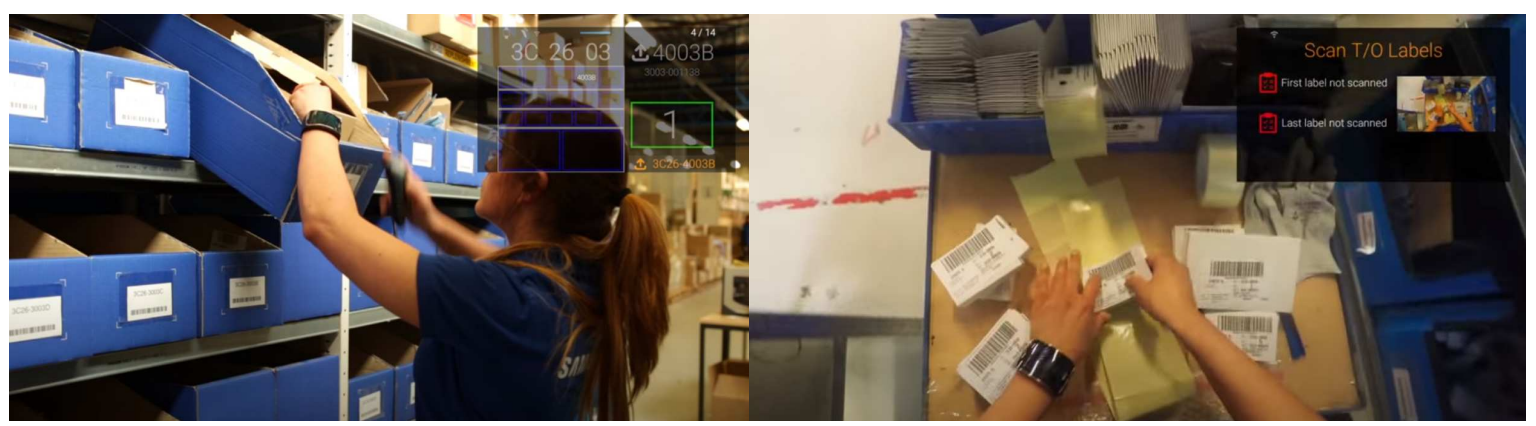

Figure 4 Samsung Vision Picking [16]

\subsection{Coca-Cola $\mathrm{HBC}$}

Coca-Cola HBC is a company based in Thessaloniki, Greece, known to everyone as a beverage company. The difference between the method of picking goods in this company and the previous two is using the device. In northern Greece, in 2019, they began this method of picking through the RealWear HMT-1, which have a more powerful appearance than Google Glass. In the virtual image in the field of view, the worker sees the picked objects, picking points and quantities. He gives instructions by voice and confirms the process. The hands-free set also includes a camera, with which the worker reads the QR code of the pallet needed when picking the goods. They combined this innovation with the Coca-Cola SAP and WMS production system for fast real-time information flow [17].

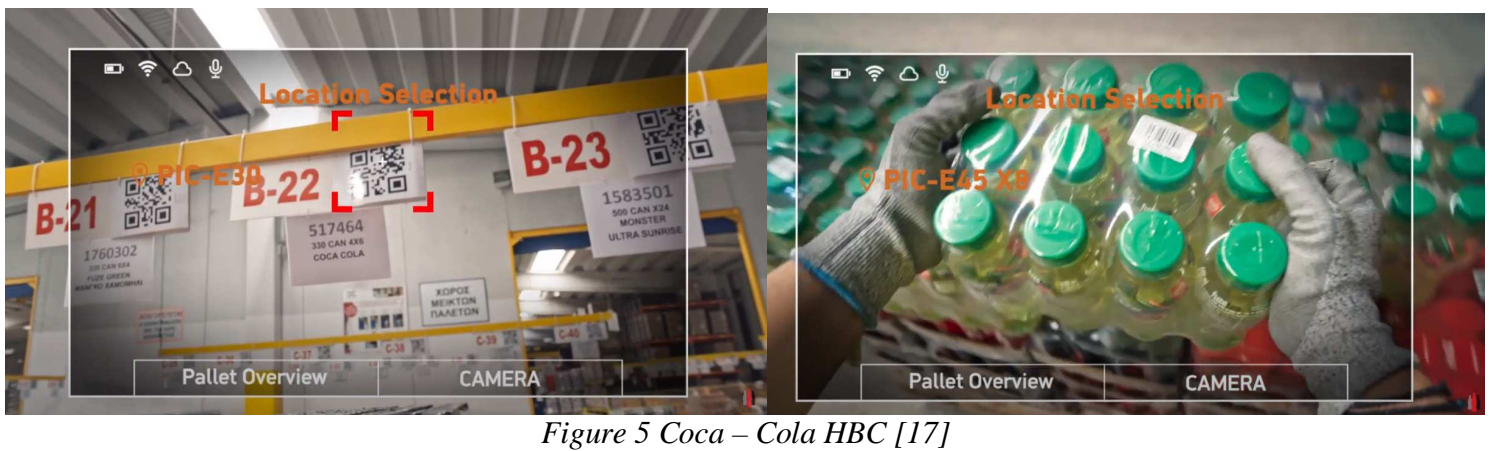

\subsection{Intel $A D C$}

The Intel distribution centre in Arizona tested vision picking in 2017. The xPick software was supplemented by Intel Recon Jet Pro glasses developed specifically for their distribution centre. These glasses are designed to fit ergonomically in a given work environment. The information about the goods is graphically displayed in the glasses. In the upper right corner, the worker sees the aisle and shelf position where the goods are located. The left part of the field of view is the remaining information, such as the product code, the number of goods and the next item. When picking up the product, a Zebra ring scanner is also used, which scans individual objects' barcodes. The system automatically notifies the employee to document (Figure 6 ) the delivery note before proceeding to the next order [18,19]. 


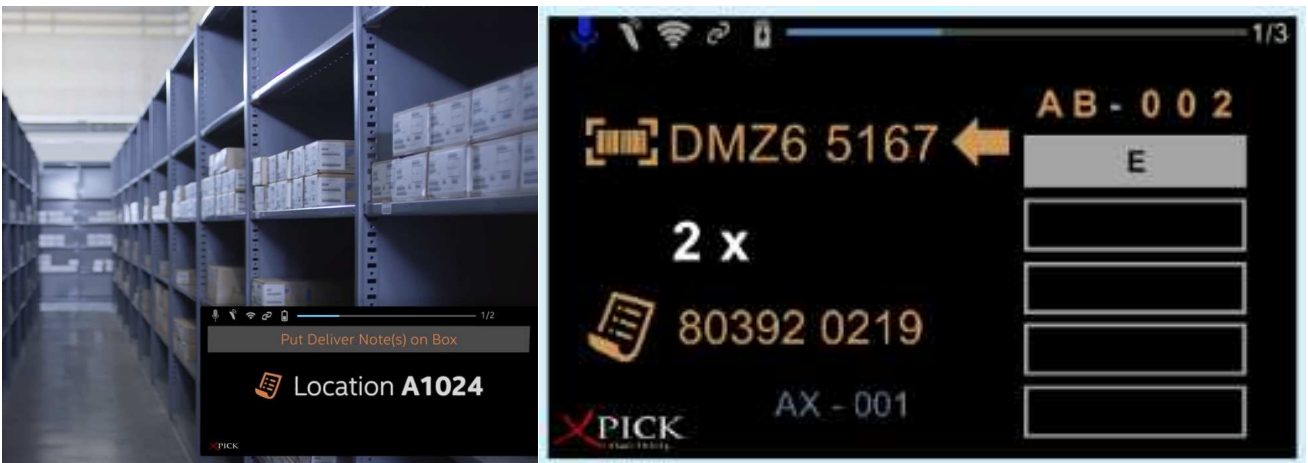

Figure 6 Intel ADC Pilot [18]

Table 1 shows the technologies used by selected companies when picking goods in a pick-by-vision manner for better clarity.

Table 1 Equipment used by selected companies for Vision Picking [authors own processing]

\begin{tabular}{|c|c|c|c|}
\hline DHL Supply Chain & SAMSUNG SDS & COCA-COLA HBC & INTEL ADC \\
\hline $\begin{array}{l}\text { Google Glass } \\
\text { ENTERPRISE EDITION }\end{array}$ & $\begin{array}{l}\text { Google Glass } \\
\text {. }\end{array}$ & & \\
\hline VUZIX M100 & SOCKET mobile & RealWear HMT-1 & \\
\hline VUZIX M300XL & scanner & & ZEBRA scanner \\
\hline ZEBRA scanner & Samsung Gear \$2 & & \\
\hline
\end{tabular}

\section{Conclusion}

Each of the analysed companies using vision picking for the distribution of goods praises the technology over time and sees great benefits. In the following points, the benefits brought by augmented reality technology for the support of warehouse logistics are subjectively evaluated:

- $\quad$ improving ergonomics at work

- $\quad$ increased safety by releasing the hands

- faster picking

- amount of information in one device

- connection to the entire warehouse system and response speed

- $\quad$ no rugged scanners and papers

- $\quad$ ease of use

- clarity of information about the goods in the facility

- $\quad$ speed of training

- use even in noisy environments

- $\quad$ eliminates the risk of causing an error to personnel

- change in the work environment and the absorption effect on the worker

These benefits are reflected in the overall increase in productivity. The error rate will be reduced many times with the introduction of vision picking.

Accuracy is very important for customer satisfaction. In the following Table 2, we can see how the use of augmented reality in selected companies has contributed.

\begin{tabular}{|l|l|l|l|}
\hline $\begin{array}{c}\text { DHL Supply } \\
\text { Chain }\end{array}$ & $\begin{array}{l}\text { SAMSUNG } \\
\text { SDS }\end{array}$ & $\begin{array}{l}\text { COCA-COLA } \\
\text { HBC }\end{array}$ & $\begin{array}{c}\text { INTEL } \\
\text { ADC }\end{array}$ \\
\hline $\begin{array}{l}\text { Productivity } \\
\text { increase by 15\% } \\
\text { speed increase } \\
\text { by 25\% }\end{array}$ & $\begin{array}{l}\text { Productivity } \\
\text { increase by } \\
12-22 \%\end{array}$ & $\begin{array}{l}\text { Increase } \\
\text { performance } \\
\text { by 6-8\% }\end{array}$ & $\begin{array}{l}\text { Speed } \\
\text { increase } \\
\text { by 29\% }\end{array}$ \\
\hline $\begin{array}{l}\text { Increased } \\
\text { accuracy }\end{array}$ & $\begin{array}{l}\text { Reduction } \\
\text { of error rate } \\
\text { by 10\% }\end{array}$ & $\begin{array}{l}\text { Accuracy } \\
99,9 \%\end{array}$ & $\begin{array}{l}\text { Error rate } \\
0 \%\end{array}$ \\
\hline
\end{tabular}

Table 2 Equipment used by selected companies for Vision Picking [authors own processing]

The analysis of the way of using augmented reality in picking goods brings added value in two points - the share of the use of augmented reality in the logistics of global companies and a description of the benefits of the technology based on research activities of these companies. It is known that more than half of the resources in the warehouse are involved in order picking work, and therefore major global companies are trying to reduce these costs. One of the innovative tools is the vision picking just researched. Selected companies (DHL Supply Chain, Samsung SDS, Coca-Cola GBC, Intel ADC) adopted this method in their operations in 2014-2020, but all these companies had uniform conclusions. Implementing augmented reality through smart glasses with appropriate software reduces errors and the risk of injury at work. On the contrary, it increases the accuracy, performance, speed and flexibility of the worker, which bears fruit in higher overall productivity. From the point of view of this issue, 
we conclude that medium and large companies' attractiveness and potential is very great. This new technology investment could be costly and unnecessary for small businesses due to the smaller number of products. We assume that vision picking will, thanks to its benefits, become an increasingly popular option for distributing goods to customers, and many new warehouses and distribution centres will adopt this technology. Smart glasses allow employees to work ergonomically and more efficiently to work hands-free and without work administration. However, these glasses have limited endurance, so manufacturers' challenge is to increase this battery capacity constantly. We are concerned that working with headsets for a long time may result in poor vision and headaches. But compared to traditional paper picking or popular barcodes and RFID scanners, this method is a much more efficient solution.

\section{Acknowledgement}

This work was supported by the Slovak Research and Development Agency under the contract No. APVV-190590, by the projects VEGA 1/0700/20, KEGA 055TUKE4/2020 granted by the Ministry of Education, Science, Research and Sport of the Slovak Republic and by the Project of the Structural Funds of the EU, ITMS code: 26220220103.

\section{References}

[1] Understanding the different types of AR devices, UX Collective [Online], Available: https://uxdesign.cc/aug mented-reality-device-types-a7668b15bf7a [02 Jan 2021], 2018.

[2] 3 different types of AR explained: marker-based, markerless \& location, Blippar [Online], Available: https://www.blippar.com/blog/2018/08/14/markerbased-markerless-or-location-based-ar-different-typesof-ar [04 Jan 2020], 2018.

[3] GEROIMENKO, V.: Augmented Reality Technology and Art: The Analysis and Visualization of Evolving Conceptual Models V'12, Proceedings of the $201216^{\text {th }}$ International Conference on Information Visualisation, pp. 445-453, 2012. doi:10.1109/IV.2012.77

[4] ŽIDEK, K., PITEL, J., ADÁMEK, M., LAZORIK, P., HOŠOVSKÝ, A.: Digital Twin of Experimental Smart Manufacturing Assembly System for Industry 4.0 Concept, Sustainability, Vol. 12, No. 9, pp. 1-16, 2020. doi:10.3390/su12093658

[5] Augmented reality gives us super human abilities and a sixth sense, www.ericsson.com [Online], Available: https://www.ericsson.com/en/blog/2018/7/augmentedreality-gives-us-super-human-abilities-and-a-sixthsense [28 Dec 2020], 2018.

[6] BIMBER, O., RASKAR, R.: Spatial Augmented Reality: Merging Real and Virtual Worlds, A K Peters/CRC Press, 2005.

[7] ISHII, H.: Tangible bits: beyond pixels, TEI '08: Proceedings of the $2^{\text {nd }}$ International conference on
Tangible and embedded interaction, pp. 15-25, 2008. doi:10.1145/1347390.1347392

[8] DI DONATO, M., FIORENTINO, M., UVA, A.E., GATTUllO, M., MONNO, G.: Text legibility for projected Augmented Reality on industrial workbenches, Computer in Industry, Vol. 70, No. June, pp. 70-78, 2015. doi:10.1016/j.compind.2015.02.008

[9] Order Picking - Definition, Types \& Process, www.zoho.com [Online], Available: https://www.zoho.com/inventory/guides/picking.html [30 Dec 2020], 2020.

[10] SCHWERDTFEGER, B.: Pick-by-Vision: Bringing HMD-based Augmented Reality into the Warehouse, Disertation work, TU Munchen. 2009.

[11] MOURTZIS, D., SAMOTHRAKIS, V., ZOGOPOULOS, V., VLACHOU, E.: Warehouse Design and Operation using Augmented Reality technology: A Papermaking Industry Case Study, $12^{\text {th }}$ CIRP Conference on Intelligent Computation in Manufacturing Engineering, Procedia CIRP, 79, pp. 574-579, 2019.

[12] KIPPER, G., RAMPOLLA, J.: Augmented Reality: An Emerging Technologies Guide to AR, Elsevier, 2012.

[13] KRESS, B.C., CHATTERJEE, I.: Waveguide combiners for mixed reality headsets: a nanophotonics design perspective, Nanophotonics, Vol. 1, No. 1, pp. 41-74. 2021.

[14] STOLTZ, M.H., GIANNIKAS, V., MCFARLANE, D., STRACHAN, J., UM, J., SRINIVASAN, R.: Augmented Reality in Warehouse Operations: Opportunities and Barriers, IFAC-PapersOnLine, Vol. 50, No. 1, pp. 12979-12984, 2017. doi:10.1016/j.ifacol.2017.08.1807

[15] Vision Picking at DHL - Augmented Reality in Logistics, www.dhl.com[Online], Available: https://www.dpdhl.com/en/media-relations/mediacenter/videos/dhl-vision-picking-pilot-project.html [25 Dec 2020], 2020.

[16] Samsung Vision Picking, [Online], Available: https://www.youtube.com/watch?v=gnUK-HTn4ZA [22 Dec 2020], 2020.

[17] Coca-Cola Hellenic Bottling Company implements smart glasses vision picking, www.controldesign.com [Online], Available: https://www.controldesign.com/industrynews/2019/c oca-cola-hellenic-bottling-company-implementssmart-glasses-vision-picking/ [30 Dec 2020], 2019.

[18] Intel ADC Pilot - Recon Jet Pro, [Online], Available: https://www.youtube.com/watch?v=E7tWoEbjP1s [30 Dec 2020], 2020.

[19] FUSKO, M., RAKYTA, M., SKOKAN, R.: How digitisation is disrupting and transforming industry, Acta Tecnología, Vol. 6, No. 1, pp. 25-30, 2020. doi:10.22306/atec.v6i1.75

\section{Review process}

Single-blind peer review process. 